\title{
Current Exercise Habits and Factors Affecting Physical Activity Participation Among University Students
}

\author{
Anatalia N. Endozo, Ph.D ${ }^{1}$ \\ ${ }^{1}$ Physical Education, College of Education, Angeles University Foundation, Philippines \\ Correspondence: Associate Professor Anatalia N. Endozo, Physical Education, Angeles University Foundation, \\ Mac Arthur Highway Angeles City, Pampanga 2009, Philippines. Tel: 63-92-1597-2101. E-mail: \\ solomon467@gmail.com
}

Received: January 17, 2019 Accepted: March 12, 2019 Online Published: March 20, 2019

doi:10.5539/gjhs.v11n4p117 URL: https://doi.org/10.5539/gjhs.v11n4p117

\begin{abstract}
Background: Physical activities are indispensable to be healthy and away from illness. Yet, students are spending time being sedentary due to rapid technological advancement. Highly active individual requires physical activity for 3 days and must accumulate at least 1500-3000 metabolic equivalent tasks (MET)-minutes per week or more days of moderate or vigorous intensity activities.

Objective: This study aimed to analyze factors affecting physical activity participation among university learners in the Philippines.

Methods: An International Physical Activity Questionnaire answered by 470 participants and modified 4 point Likert scale questionnaires was utilized.

Results: There were 222 females (47\%), 248 males (53\%), and p-value $<0.05$ adoted to justify the significance of the factors in this study.

Conclusion: This study justified that most of the participants cannot engaged in physical activities due to lack of time. Future research with larger sample groups to accurately identify the factors and recommend changes to enhance participation is encouraged.
\end{abstract}

Keywords: physical activity, factors, barriers exercise, PE participation

\section{Introduction}

Physical activity plays an important role in improving and maintaining the health and well-being of every individual. Rogers, Carter, Williams, and Courneya (2018) stated that about a third of the world's population seems not interested in physical activity. The healthcare sector offers a variety of resources that can promote physical activity programs in tertiary institutions (Lobelo, Stoutenberg, \& Hutber, 2014).

Zwolinsky, McKenna and Pringle (2016) stated that there is a need to recognize the adoption of active lifestyles programs and the introduction of sport physical activity to attract inactive audiences. Warburton, Nicol, and Bredin (2006) regular physical activity prevent musculoskeletal disorders such as mechanical low back pain, neck, shoulder pain and, assist to decrease the risk of developing coronary heart diseases. Withall, Jago, and Fox (2011) affirmed that walking in alone; lack of facilities and inappropriate communication strategies hinders people to engage in physical activity.

In Canada, $85 \%$ of adults and over $90 \%$ of youth do not attain the recommended minimum of 150 minutes of moderate to vigorous physical activity (PA) per week (Bailey, Hillman, Arent, \& Petitpas 2013). Physical inactivity is responsible for about $6 \%$ of coronary heart disease, $7 \%$ of type 2 diabetes, $10 \%$ of breast cancer, and $9 \%$ of the premature birth worldwide, all mentioned can control through physical activities including climbing stairs instead of elevators, lifting of things instead of using auto wheels, adopt standing to sitting while waiting (Belanger, Sabiston, Barnett, Contreras, \& O’Loughlin 2015; Eather, Morgan, \& Lubans, 2013; Haskell et al., 2007).

Saadan, Jano, Sidek, and Bokhari (2015) affirmed that students entering college have a heavier weight and gaining more due to a lack of engagement in physical activities. Jensen (2007) investigated factors contributing to why students adding weight, moreover, the related study seems limited in the context of the Philippine students. Thus, 
this study aims to analyze factors affecting physical activity participation among university students in Region III, Philippines.

\section{Materials and Methods}

\subsection{Participants and Research Design}

A sample of 470 adopted. There were 222 females (47\%) and 248 males (53\%) in this study. The samples included many more males than females. International Physical Activity, factors to physical activity and modified 4 point Likert scale questionnaires based from Sallis and Patrick (1994), Arzu et al. (2006) were used in the study respectively.

\subsection{Data Analysis}

The values expressed as mean standard error. Statistical significance was determined using a one-way analysis of variance (ANOVA) followed at the initial stage, the variances of the physical activity categories noticed not equal, Kruskal-Wallis test considered instead of ANOVA. Stata 13 and SPSS version was utilized as the statistical tools, KMO sampling adequacy of .823 achieved, and alpha equal to .849 achieved. Thus, descriptive statistics presented (Oluyinka et al., 2013; Ayodele et al., 2018).

\section{Search Results}

A total number of thirty respondents did not answer $70 \%$ of the asked questions and excluded from this study. A total of $56.60 \%$ identified to be inactive. It appeared to be no physical activity or some activities were reported but not enough to meet the categories 2 or 3 . Nevertheless, a total good number of $33.19 \%$ were doing 3 more days of vigorous activity of at least 20 minutes per day or 5 or more days of moderate-intensity activity and/or walking of at least 30 minutes per day or 5 or more days of any combination of walking, moderate-intensity or vigorous intensity activities achieving a minimum of at least 600 MET-minutes/week and were identified as moderately active. Overall, a $10.21 \%$ of the respondents were classified as highly active doing vigorous activity on at least 3 days and accumulating at least 1500 MET-minutes/week or 7 or more days of any combination of walking, moderate or vigorous-intensity activities accumulating at least 3000 MET-minutes/week.

The World Health Organization emphasized the importance of frequency, intensity, type of exercise and time (FITT) principle as necessary to produce health benefits. The enjoyment and social networks offered by physical activity are clearly important motivators and the reasons for participation could be differ among individuals (Allender et al., 2007). Conclusively, Lobelo et al. (2014) physical activity counseling and referral systems have potentials to improve physical activity participation by complementing and leveraging other efforts.

Table 1. Description of factors affecting physical activity participation

\begin{tabular}{|c|c|c|c|}
\hline Factors Affecting Physical Activity Participation & $\begin{array}{l}\text { Mean-A } \\
\text { ll }\end{array}$ & $\begin{array}{l}\text { Male } \\
\text { s }\end{array}$ & $\begin{array}{l}\text { Femal } \\
\text { es }\end{array}$ \\
\hline 1. I've been thinking about exercise is difficult and too tiring & 2.24 & 2.23 & 2.26 \\
\hline 2. I have no energy as much as to be able to do exercise. & 2.2 & 2.12 & 2.09 \\
\hline Lack of energy Score & 4.35 & 4.35 & 4.35 \\
\hline $\begin{array}{l}\text { 3. I've been thinking about other recreational activities with my friends are more entertaining } \\
\text { than exercise. }\end{array}$ & 2.85 & 2.79 & 2.91 \\
\hline 4. I have not been thinking about exercise has positive effecs on my health. & 1.7 & 1.75 & 1.64 \\
\hline Lack of motivation Score & 4.54 & 4.54 & 4.55 \\
\hline 5. I've been worried about my looks when I exercise. & 1.93 & 1.93 & 1.94 \\
\hline 6. I have not been thinking about my ability to exercise. & 2.08 & 2.14 & 2.02 \\
\hline Lack of Self-confidence Score & 4.01 & 4.06 & 3.95 \\
\hline Sum of Internal Factors Score & 12.91 & 12.95 & 12.86 \\
\hline 7. There is no fitness center that I could get into. & 2.06 & 2.03 & 2.08 \\
\hline 8. I have no exercise equipment at home that I use. & 2.51 & 2.34 & 2.69 \\
\hline Lack of Resource Score & 4.56 & 4.37 & 4.77 \\
\hline
\end{tabular}


9. My family or friends do not encourage me to exercise.

10. My parents give academic success priority over exercise.

Lack of Support

11. I have no leisure time for exercise because of my busy lesson schedule.

12. I have no leisure time for exercise because of my social and family responsibilities.

Lack of Time

Sum of External Factors Score

Sum of factors score

\begin{tabular}{lll}
1.73 & 1.74 & 1.72 \\
2.35 & 2.25 & 2.47 \\
4.09 & 3.99 & 4.19 \\
2.84 & 2.74 & 2.95 \\
2.35 & 2.23 & 2.49 \\
5.2 & 4.98 & 5.44 \\
$\mathbf{1 3 . 8 4}$ & $\mathbf{1 3 . 3 4}$ & $\mathbf{1 4 . 4 1}$ \\
$\mathbf{2 6 . 7 5}$ & $\mathbf{2 6 . 2 9}$ & $\mathbf{2 7 . 2 6}$ \\
\hline & &
\end{tabular}

It can be gleaned on the table that there were differences in the mean factors to physical activity considering the gender. Female respondents have higher rates on almost all questions compare to male respondents. The total score of the external factors was significantly higher than the score of the internal factors. It was identified that lack of time was one of the most important external factor to physical activity participation with the mean of 5.2 while, lack of motivation with the mean of 4.55 was the most important internal factor that somewhat affect the participation of the respondents in doing physical activity. In a survey conducted in Singapore, the percentage of Singaporeans who exercise increased from 20 percent in 2001 to 22.4 percent in 2007 . This study identified three factors to exercise, No time (54.6 percent), too tired (12.1 percent) and too lazy (11.6 percent).The study strongly supported the findings that lack of time and lack of motivation to exercise affected the respondents' participation to physical activities. This means that respondents find exercises difficult and too tiring, also by some means they prefer other recreational activities with their friends as they find it more entertaining.

Nevertheless, respondents were also affected by external physical activity factors like lack of resources, lack of support and lack of time in particular. Some external factors includes lack of fitness center or no exercise equipment at home, also they are encourage by friends and family to exercise as parents give academic success priority over exercise (Endozo, 2013). Lastly and most evidently no leisure time for exercise because of the busy lesson schedule and social and family responsibilities. Allender (2006) weight management, enjoyment, social interaction and support were more common reasons for people being physically active.

Table 2. Relationship of respondent's profile and factors to physical activity participation

\begin{tabular}{lllllll}
\hline Group & Observed & Mean & Std. Err. & Std.Dev. & [95\% Conf.Interval] \\
\hline Male & 248 & 26.69 & .46 & 5.08 & 25.39 & 27.19 \\
Female & 222 & 27.26 & .47 & 4.90 & 26.33 & 28.19 \\
Combined & 470 & 26.75 & .33 & 5.04 & 26.10 & 27.39 \\
\hline
\end{tabular}

Table 2 indicated that sum of physical activity internal factors was not significantly different among male and female respondents while the physical activity external factors of male is less with female respondents. The total mean score of the factors of males were less than those of the females. Two-sample $t$ test with equal variances considered significant as one tailed test significant at $10 \%$ level of significant. The diff (mean) $t=1.4785$; Ho: diff $=0$; degrees of freedom $=$ Ha: diff $<0$; Ha: diff! $=0$; Ha: diff $>0$. However, this study reported $\operatorname{Pr}(\mathrm{T}<\mathrm{t})=0.0703$; $\operatorname{Pr}(|\mathrm{T}|>|\mathrm{t}|)=0.1406 ; \operatorname{Pr}(\mathrm{T}>\mathrm{t})=0.9297$. The result implied that male respondents find more resources for fitness like fitness center or gym to do physical activity.

In addition, male respondents are more inclined to go to fitness center/gym with friends or family member/s and put their time and energy to such activities over academic and other responsibilities. Also, fun, enjoyment and social support were reported more often as predictors of participation and non-participation than perceived health benefits. 
Table 3. Relationship of respondent's profile and physical activity

\begin{tabular}{lllll}
\hline Gender & Low & Moderate & High & Total \\
\hline Male & 134 & 90 & 24 & 248 \\
Female & 132 & 66 & 24 & 222 \\
\hline
\end{tabular}

Table 3, indicated female respondents physical activity lower than that of the male respondents. It was supported with the fact that going to fitness center is more appealing to male and they are more aware of the benefits of exercises like strengthening of the body and mind, enhancement of self-confidence and self-expression. Contradictory, dance is more appealing to girls than boys. Thus, Figure 1 of this study presents male and female physical activity of the respondents.

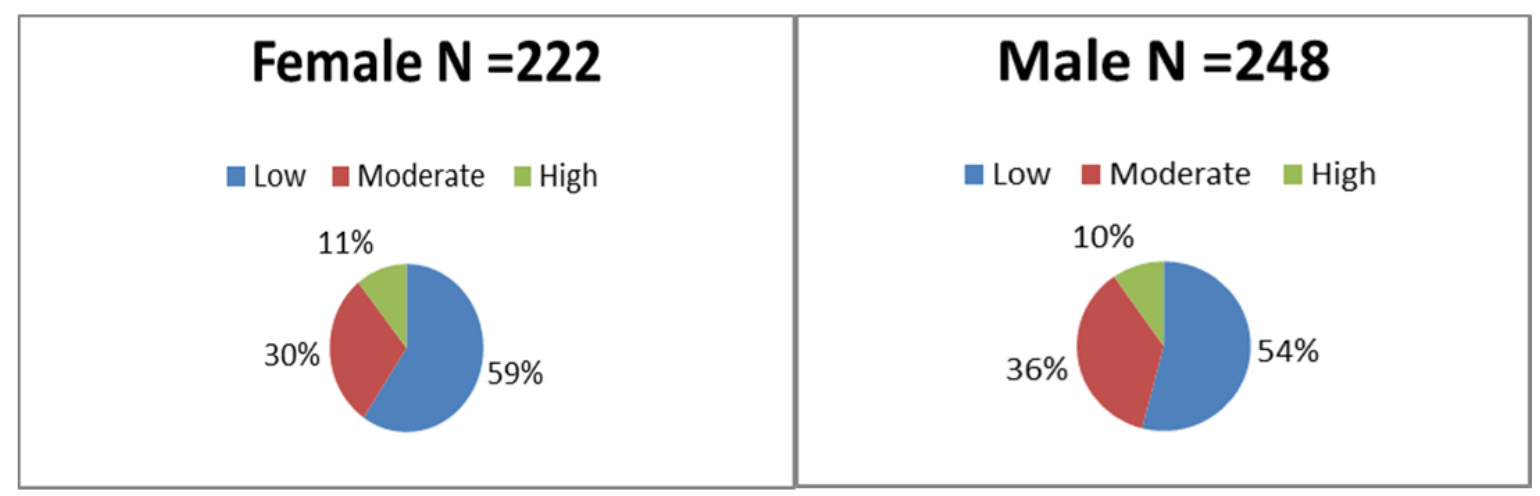

Figure 1. Respondents physical activity percentage details

Figure 1 justified that the males students adopted in this study claimed moderately involved in physical activities with $36 \%$ against $30 \%$, this study also suggested that physical activities at both ends claimed low at female with $59 \%$ and male with $54 \%$. Conclusively, Kendall's tau-b indicated 0.0414 , ASE $=0.063$ of the total sample of 470 respondents to supports the findings of this study.

Azevedo et al. (2007) regardless of guidelines adopted, men were more active than women. Levels of physical activity for men and women expected not to be equal, and variables related to activity levels may not be consistent across the genders, interventions encouraging physical activity ought to take these variations under consideration. Studies argued that aerobic physical activity classes were attended primarily by females (Barr-Anderson et al., 2013; Crawford \& Eklund, 1994; Ryan et al., 2014). Therefore, it was also expected that female respondents of this study would prefer exercising in a structured settings for both aerobic activity and weight training, more so than males (Chomitz et al., 2009; Hallal et al., 2012).

Allender et al. (2006) in his study supported the impact of sports, outdoor games, or physical exercise on children' physical education learning. The study claimed that young girls are motivated and engaged in physical activity participation in order to maintain a slim body shape. Adults recognized the significance of sport and physical activity in staving off the effects of aging and providing a social support network.

Supportively, most studies identified lacking confidence, competence, motivation and time as their reasons for participation and non-participation in sport and physical activity (Allender et al., 2006; Barr-Anderson et al., 2013; Ryan et al., 2014).

Table 4. Factors to physical activity and current exercise habits

\begin{tabular}{llll}
\hline Category & Observed (Obs) & Percent (\%) & Rank Sum \\
\hline Low/Inactive & 266 & $57 \%$ & 16745.00 \\
Moderately Active & 156 & $33 \%$ & 7925.50 \\
Highly Active & 48 & $10 \%$ & 3059.50 \\
\hline
\end{tabular}


Table 4, reported a Kruskal-Wallis $H$ test conducted to determine barriers and current exercise habits when categorized in term of inactive $(n=266)$, moderate $(n=156)$ and highly active $(n=48)$ among the respondents. A Kruskal-Wallis $\mathrm{H}$ test showed that there was a statistically significant difference in among categorized as the observed $\chi^{2}$-value indicated 6.798 , with degrees of freedom of equal and significance level of 0.0334 . Towards getting the relationship for factors to physical activity, at first, the Barlett's test was used, the variances of the physical activities categories are not equal, and due to that, ANOVA is inappropriate instead the Kruskal-Wallis test was used.

This study noticed no tie data among the categorized. Therefore, tie assumptions not considered. There is a significant relationship between factors scores of the respondents in different current exercise habits categories. Respondents' current exercise habit varies considering the preferences, choices, capabilities, abilities and such factors. The responses of the students on the factors to physical activity significantly differed based on how the respondents coped up and dealt with all the factors to participate in physical activity.

\section{Review Outcomes}

Advancement in technology and labor-saving devices has afforded people greater ease and convenience at work, school and at home. These have resulted in more free time, which either filled up more work or spend in recreation. In order to achieve and maintain a healthy body, regular physical activity are required; it will help to reduce obesity. People should be able to overcome obesity through physically active lifestyles (Donnelly \& Lambourne, 2011; Rasberry et al., 2011; Thompson et al., 2010). Pate et al., (1995) emphasized that regular physical activity of sixty minutes daily improves muscle strength and endurance and reduces the risk of developing chronic diseases. On the other hand, Mcinnis et al (2003) noted that about 10 minutes to 30 minutes physical activity is the best predictor for weight loss

A survey on prevalence of obesity among adults and youth conducted by Ogden et al. (2015) affirmed that the number of obese Filipino adults increased by 14.5 percentage points, from 16.6 percent in 1993 to 31.1 percent in 2013. This means that three (3) out of ten (10) Filipino adults are obese, also, among 10 to 19 years old, the prevalence increased by 2.5 points, from 5.8 percent in 2003 to 8.3 percent in 2013, outcome justified that over nutrition is not common with rich but rampant among the poor. Haines et al. (2007); Dunstan et al. (2012); Tudor et al., (2007) found consistent.

Obesity and idle lifestyles face doubled in countries such as the Philippines, Indonesia, Malaysia and Thailand (Khor, 2008) addressing obesity cause by inactivity and other factors is still a big challenge in the Philippines and there is no single factor that causes it.

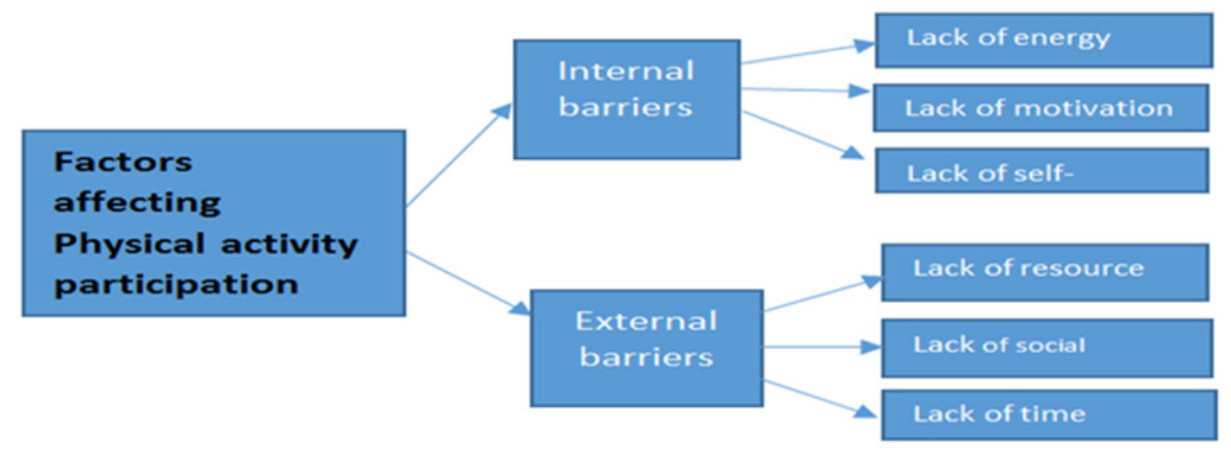

Figure 2. Research Framework of the study

\section{Discussion}

Findings of this study revealed that majority of the participants have low level of participation in physical activity. Furthermore, data indicated that male respondents are more physically active than female respondents. Data showed than female's physical activity was lower than those of the males. Lack of time was one of the most important external factors to physical activity participation while lack of motivation was the most important internal factor that somewhat affect the participation of the respondents in doing physical activity.The sum of physical activity internal factors was not significantly different among male and female respondents while the physical activity external factors of male are less with female respondents. Overcoming factors is a skill that will help individual to find ways to stay physically active despite various factors (Brown, 2005). Participation in physical activity among university students is affected by set of factors and that are unique to this population 
(Rimmer, Riley, Wang, Rauworth, \& Jurkowski, 2004).

\section{Conclusion}

There is a significant relationship between factors scores of the respondents' physical activity participation categories. The respondents' current exercise habit varies considering the preferences, choices, capabilities, abilities and such factors. It is imperative to identify the daily physical activities, time spent in it, and its intensity (Brown, 2005; Thompson \& Wankel, 1980; Schutzer \& Graves, 2004). Future research should utilize this information to develop intervention strategies that have a greater likelihood of success. In addition, suggested that the theoretical and evidence base informing policy and health promotion is limited and more work essentials to be done in this area.

\section{Acknowledgments}

We are thankful to the Angeles University Foundation and Baliuag University. We are also thankful to all the people who in one way or the other contributed in the completion of this study.

\section{Funding}

There was no fund for this study except library access support from the Angeles University Foundation and Baliuag University library.

\section{Competing Interests Statement}

The author declares that there are no competing or potential conflicts of interest.

\section{References}

Allender, S., Cowburn, G., \& Foster, C. (2006), Understanding participation in sport and physical activity among children and adults: A review of qualitative studies. Health education research, 21(6), 826-835. https://doi.org/10.1093/her/cyl063

Andersen, L. B. (1993). Tracking of cardiovascular disease risk factors including maximal oxygen uptake and physical activity from late teenage to adulthood: an 8 year follow-up study. Journal of Internal Medicine. https://doi.org/10.1111/j.1365-2796.1993.tb00748.x

Arzu, D., Tuzun, E. H., \& Eker, L. (2006). Perceived barriers to physical activity in university students. Journal of sports science \& medicine, 5(4), 615.

Ayodele, S. O., Oga, O. E., Bundot, Y. G., \& Ogbari, M. E. (2016, October). Role of power supply towards e-learning acceptance: VBSEM-AMOS. In 2016 6th International Conference on Information Communication and Management (ICICM) (pp. 151-155). IEEE.

Azevedo, M. R., Araújo, C. L. P., Reichert, F. F., Siqueira, F. V., da Silva, M. C., \& Hallal, P. C. (2007). Gender differences in leisure-time physical activity. International Journal of Public Health, 52(1), 8. https://doi.org/10.1007/s00038-006-5062-1

Bailey, R., Hillman, C., Arent, S., \& Petitpas, A. (2013). Physical activity: An underestimated investment in human capital?. Journal of physical activity and health, 10(3), 289-308. https://doi.org/10.1123/jpah.10.3.289

Barr-Anderson, D. J., Adams, Wynn, A. W., DiSantis, K. I., \& Kumanyika, S. (2013). Family focused physical activity, diet and obesity interventions in A frican-A merican girls: A systematic review. Obesity Reviews, 14(1), 29-51. https://doi.org/10.1111/j.1467-789X.2012.01043.x

Bélanger, M., Sabiston, C. M., Barnett, T. A., O'Loughlin, E., Ward, S., Contreras, G., \& O'Loughlin, J. (2015). Number of years of participation in some, but not all, types of physical activity during adolescence predicts level of physical activity in adulthood: Results from a 13-year study. International Journal of Behavioral Nutrition and Physical Activity, 12(1), 76. https://doi.org/10.1186/s12966-015-0237-x

Brown, S. A. (2005). Measuring perceived benefits and perceived barriers for physical activity. American Journal of Health Behavior, 29(2), 107-116. https://doi.org/10.5993/AJHB.29.2.2

Chomitz, V. R., Slining, M. M., McGowan, R. J., Mitchell, S. E., Dawson, G. F., \& Hacker, K. A. (2009). Is there a relationship between physical fitness and academic achievement? Positive results from public school children in the Northeastern United States. Journal of School Health, 79(1), 30-37. https://doi.org/10.1111/j.1746-1561.2008.00371.x

Donnelly, J. E., \& Lambourne, K. (2011). Classroom-based physical activity, cognition, and academic 
achievement. Preventive medicine, 52, S36-S42. https://doi.org/10.1016/j.ypmed.2011.01.021

Dunstan, D. W., Howard, B., Healy, G. N., \& Owen, N. (2012). Too much sitting-a health hazard. Diabetes Research and Clinical Practice, 97(3), 368-376. https://doi.org/10.1016/j.diabres.2012.05.020

Eather, N., Morgan, P. J., \& Lubans, D. R. (2013). Improving the fitness and physical activity levels of primary school children: Results of the Fit-4-Fun group randomized controlled trial. Preventive medicine, 56(1), 12-19. https://doi.org/10.1016/j.ypmed.2012.10.019

Endozo Larce, A. (2013). SELF TESTING AND FITNESS ACTIVITIES: An Instructional Modules for College AUF PE Students. In The Dubai International Conference in Higher Education 2013 (p. 292). Universal-Publishers.

Haines, J., Neumark Sztainer, D., Wall, M., \& Story, M. (2007). Personal, behavioral, and environmental risk and protective factors for adolescent overweight. Obesity, 15(11), 2748-2760. https://doi.org/10.1038/oby.2007.327

Hallal, P. C., Andersen, L. B., Bull, F. C., Guthold, R., Haskell, W., Ekelund, U., \& Lancet Physical Activity Series Working Group. (2012). Global physical activity levels: surveillance progress, pitfalls, and prospects. The lancet, 380(9838), 247-257. https://doi.org/10.1016/S0140-6736(12)60646-1

Haskell, W. L., Lee, I. M., Pate, R. R., Powell, K. E., Blair, S. N., Franklin, B. A.,\& Bauman, A. (2007). Physical activity and public health: updated recommendation for adults from the American College of Sports Medicine and the American Heart Association. Circulation, 116(9), 1081. https://doi.org/10.1161/CIRCULATIONAHA.107.185649

Jensen, J. A. (2007). Weight stability and influences upon eating and exercise behaviors among college students.

Khor, G. L. (2008). Food-based approaches to combat the double burden among the poor: challenges in the Asian context. Asia Pacific Journal of Clinical Nutrition, 17(S1), 111-115.

Lobelo, F., Stoutenberg, M., \& Hutber, A. (2014). The exercise is medicine global health initiative: a 2014 update. Br J Sports Med, bjsports-2013. https://doi.org/10.1136/bjsports-2013-093080

Lobstein, T., Baur, L., \& Uauy, R. (2004). Obesity in children and young people: a crisis in public health. Obesity reviews, 5, 4-85. https://doi.org/10.1111/j.1467-789X.2004.00133.x

Mcinnis, K. J., Franklin, B. A., \& Rippe, J. M. (2003). Counseling for physical activity in overweight and obese patients. American family physician, 67(6), 1249-1256.

Ogden, C. L., Carroll, M. D., Fryar, C. D., \& Flegal, K. M. (2015). Prevalence of obesity among adults and youth: United States, 2011-2014 (pp. 1-8). Washington, DC: US Department of Health and Human Services, Centers for Disease Control and Prevention, National Center for Health Statistics.

Oluyinka, S., Shamsuddin, A., Ajabe, M. A., \& Enegbuma, W. I. (2013). A study of electronic commerce adoption factors in Nigeria. IJISCM, 6(4), 293-315. https://doi.org/10.1504/IJISCM.2013.060974

Pate, R. R., Pratt, M., Blair, S. N., Haskell, W. L., Macera, C. A., Bouchard, C., \& Kriska, A. (1995). Physical activity and public health: a recommendation from the Centers for Disease Control and Prevention and the American College of Sports Medicine. Jama, 273(5), 402-407. https://doi.org/10.1001/jama.1995.03520290054029

Rasberry, C. N., Lee, S. M., Robin, L., Laris, B. A., Russell, L. A., Coyle, K. K., \& Nihiser, A. J. (2011). The association between school-based physical activity, including physical education, and academic performance: a systematic review of the literature. Preventive medicine, 52, S10-S20. https://doi.org/10.1016/j.ypmed.2011.01.027

Rimmer, J. H., Riley, B., Wang, E., Rauworth, A., \& Jurkowski, J. (2004). Physical activity participation among persons with disabilities: barriers and facilitators. American Journal of Preventive Medicine, 26(5), 419-425. https://doi.org/10.1016/j.amepre.2004.02.002

Rogers, L. Q., Carter, S. J., Williams, G., \& Courneya, K. S. (2018). Physical activity. In Handbook of Cancer Survivorship (pp. 287-307). Springer, Cham. https://doi.org/10.1007/978-3-319-77432-9_15

Ryan, A. S., Ge, S., Blumenthal, J. B., Serra, M. C., Prior, S. J., \& Goldberg, A. P. (2014). Aerobic exercise and weight loss reduce vascular markers of inflammation and improve insulin sensitivity in obese women. Journal of the American Geriatrics Society, 62(4), 607-614. https://doi.org/10.1111/jgs.12749

Saadan, R., Jano, Z., Sidek, S., \& Bokhari, M. (2015). Perceived Barriers in Physical Activities among University 
Students. Journal of Human Capital Development (JHCD), 8(1), 39-46.

Sallis, J. F., \& Patrick, K. (1994). International Physical Activity Questionnaire. Through Physical Education, Illinois: Human Kinetics.

Thompson, J. L., Jago, R., Brockman, R., Cartwright, K., Page, A. S., \& Fox, K. R. (2010). Physically active families-de-bunking the myth? A qualitative study of family participation in physical activity. Child: care, health and development, 36(2), 265-274. https://doi.org/10.1111/j.1365-2214.2009.01051.x

Tudor-Locke, C., Ainsworth, B. E., Adair, L. S., Du, S., Lee, N., \& Popkin, B. M. (2007). Cross-sectional comparison of physical activity and inactivity patterns in Chinese and Filipino youth. Child: care, health and development, 33(1), 59-66. https://doi.org/10.1111/j.1365-2214.2006.00612.x

Warburton, D. E., Nicol, C. W., \& Bredin, S. S. (2006). Health benefits of physical activity: the evidence. Cmaj, 174(6), 801-809. https://doi.org/10.1503/cmaj.051351

Withall, J., Jago, R., \& Fox, K. R. (2011). Why some do but most don't. Barriers and enablers to engaging low-income groups in physical activity programmes: A mixed methods study. BMC public health, 11(1), 507. https://doi.org/10.1186/1471-2458-11-507

Zwolinsky, McKenna, \& Pringle. (2016). How Can the Health System Benefit from Increasing Participation in Sport, Exercise and Physical Activity?. In Sports-Based Health Interventions (pp. 29-52). Springer, New York, NY.

\section{Copyrights}

Copyright for this article is retained by the author(s), with first publication rights granted to the journal. This is an open-access article distributed under the terms and conditions of the Creative Commons Attribution license (http://creativecommons.org/licenses/by/4.0/). 